\title{
Estrogen inhibits the effects of obesity and alcohol on mammary tumors and fatty liver
}

\author{
JINA HONG ${ }^{1,3^{*}}$, VALERIE B. HOLCOMB ${ }^{1 *}$, KYOKO KUSHIRO $^{2}$ and NOMELÍ P. NÚÑEZ ${ }^{1,2}$ \\ ${ }^{1}$ Department of Nutritional Sciences; ${ }^{2}$ Institute for Cellular and Molecular Biology, The University of \\ Texas at Austin, School of Human Ecology, 1 University Station, Austin, TX 78712, USA
}

Received May 31, 2011; Accepted July 1, 2011

DOI: 10.3892/ijo.2011.1162

\begin{abstract}
The risk of developing breast cancer and fatty liver is increased by alcohol consumption. The objective of the present study was to determine if obesity and exogenous estrogen supplementation alter the effects of alcohol on mammary tumorigenesis and fatty liver. Ovariectomized female mice were (1) fed diets to induce overweight and obese phenotypes, (2) provided water or $20 \%$ alcohol, (3) implanted with placebo, low- or high-dose estrogen pellets and (4) injected with Met-1 mouse mammary cancer cells. Alcohol-consuming mice were more insulin sensitive and developed larger tumors than water consuming mice. Obese mice developed slightly larger tumors than control mice. Alcohol consumption and obesity increased growth factors, hepatic steatosis, activation of Akt, and inhibited the caspase- 3 cascade. Estrogen treatment triggered the loss of body fat, induced insulin sensitivity, suppressed tumor growth, reduced growth factors and improved hepatic steatosis. Results show that the effects of alcohol on mammary tumor and fatty liver are modified by obesity and estrogen supplementation.
\end{abstract}

\section{Introduction}

Breast cancer is the second leading cause of cancer death among women in the United States (1). In 2010, the American Cancer Society predicted the diagnosis of 207,000 new cases of invasive breast cancer with 40,000 resulting in death (1).

Correspondence to: Dr Nomelí P. Núñez, The University of Texas at Austin, College of Natural Sciences, School of Human Ecology, Department of Nutritional Sciences, 1 University Station A2703, PAI 5.14, Austin, TX 78712, USA

E-mail: nomeli@mail.utexas.edu

Present address: ${ }^{3}$ Princeton University, Department of Molecular Biology, Princeton University, Princeton, NJ 08544, USA

${ }^{*}$ Contributed equally

Key words: alcohol, obesity, estrogen, breast cancer, postmenopause, fatty liver
Many modifiable risk factors, including alcohol, obesity and estrogen therapy have been shown to influence breast cancer development (1).

Epidemiological studies show alcohol increases breast cancer risk in a dose-dependent manner (2). The relative risk of developing breast cancer increases $\sim 10 \%$ for every drink consumed $(3,4)$. Alcohol consumption also increases the invasiveness and metastatic potential of breast cancer $(5,6)$. In fact, women who ingest alcohol have a higher probability of developing a more advanced stage of breast cancer $(2,6)$. Evidence suggests alcohol may affect tumor growth. Epidemiological and animal studies report a positive connection between alcohol and mammary tumor cell proliferation (5,7-9). Alcohol increases the production of growth hormones (e.g., insulin, leptin) which may modulate tumor growth and metastases (4). Hormones like insulin and leptin stimulate the phosphoinositide 3-kinase (PI3K)/Akt signaling pathway: a pathway that plays an important role in breast cancer progression. Abnormal activation of Akt has been observed in various types of cancer $(5,10,11)$. Studies suggest alcohol consumption leads to the activation of the PI3K/Akt signaling pathway $(12,13)$. Moreover, not only does alcohol affect breast carcinogenesis, but the risk of developing hepatic steatosis or fatty liver increases with chronic alcohol consumption $(14,15)$.

Obesity in postmenopausal women increases the risk of death and mortality from breast cancer (16-18). Approximately $30-50 \%$ of breast cancer deaths may be attributed to excess body weight, which translates to 11,000-18,000 deaths per year (19). Adipose tissue is capable of producing multiple factors, such as estrogen, leptin, adiponectin, insulin-like growth factor-1 (IGF-1) and other cytokines, which have been shown to influence various processes involved in carcinogenesis (17,20-22). In particular, obesity increases bio-available insulin and IGF-1 in the blood due to a reduction in IGF-1 binding protein abundance (23). The elevated insulin levels stimulate phosphorylation of the insulin receptor (IR) and IGF-1R and may trigger intracellular signals through the PI3K pathway in mammary gland and breast tumor tissue (24). In addition to breast cancer risk, obesity increases the risk of developing fatty liver (25-27). It is unclear if the effects of alcohol on breast cancer are modified by body weight.

Estrogen is produced largely by the ovaries until menopause where estrogen production shifts to peripheral tissues, like adipose tissue (28). As a result, obese postmenopausal women 
have higher estrogen levels compared to lean postmenopausal women (20). Data suggest breast cancer risk increases with obesity and alcohol through the hormone estrogen $(20,22,29$ 37). After menopause, estrogen replacement therapy (ERT) is used to protect women from hypo-estrogenic problems, such as loss of bone mineral density (BMD). Postmenopausal women receiving ERT have a greater risk of breast cancer with alcohol consumption (36). One study showed the relative risk of developing breast cancer in abstainers was 1.0, alcohol consumers was 1.28 , estrogen-therapy recipients was 1.45 and those consuming alcohol plus estrogen was 2.08 (37). A cross-sectional study reported elevated levels of circulating estrogen in women who drink. More specifically, women who drink more than one drink per day have a $20 \%$ increase in serum estrogen levels compared to abstainers (38). Experimental studies also show estrogen promotes proliferation and survival of cancer cells in both normal and transformed epithelial cells of the mammary gland (29,39). Alcohol may affect the response of breast cancer cells to these effects of estrogen.

In the present study, our goal is to analyze the effect of alcohol consumption, diet-induced obesity and estrogen supplementation on breast cancer in ovariectomized mice that mimic the postmenopausal state. To assess the simultaneous effects of these three risk factors on tumor growth, we injected Met-1 mammary tumor cells subcutaneously into mice fed a $30 \%$ calorie restricted, low-fat or high-fat diet, and consuming either water or $20 \%$ alcohol in the drinking water. To assess the impact of these factors on tumor growth, control and obese mice consuming water and alcohol were implanted with pellets delivering either a low or high dose of estrogen, and then injected with Met-1 tumor cells. Results show obesity enhanced Met-1tumor growth rate while alcohol had no effect. The dramatic loss of body fat and concomitant decrease in phosphorylated Akt was associated with a drastic inhibition of Met-1 tumor growth observed after estrogen treatment. Additionally, liver steatosis was promoted by alcohol and obesity, which was improved by estrogen treatment. Our results suggest these breast cancer-risk factors may modulate mammary tumorigenesis through hormones associated with adipose tissue and the activation of Akt.

\section{Materials and methods}

Animals and diets. We purchased 135 6-week-old, ovariectomized FVB/N female mice from the Jackson Laboratory (Bar Harbor, MA, USA). The animals were singly housed in pathogenfree cages according to National Institutes of Health (NIH) guidelines. All procedures were approved by the Institutional Animal Care and Use Committee of the University of Texas at Austin. Mice were randomized to receive either a low fat (LF; $10 \%$ kcal from fat) or high fat (HF; 60\% kcal from fat) diet. Mice had free access to either water or $20 \%$ alcohol in the drinking water. All procedures were performed as previously described (40).

Estrogen treatment. Mice received either estrogen or placebo pellets after 19 weeks on the study. The pellets provided 0.0 (placebo), 0.18 or $0.72 \mathrm{mg}$ of $17 \beta$-estradiol (E2) over a 90-day period. Pellets were purchased from Innovative Research of America (Sarasota, FL, USA).
Glucose- and insulin-tolerance tests. We examined insulin sensitivity in mice using the glucose-tolerance test (GTT) and insulin-tolerance test (ITT) as previously described (41).

Cancer cells and tumor measurement. Estrogen receptor (ER)negative Met-1 mouse mammary cancer cells were cultured in Dulbecco's modified Eagle's medium (DMEM) supplemented with $10 \%$ fetal bovine serum (FBS) and $2 \mathrm{mM}$ penicillinstreptomycin (Invitrogen, Carlsbad, CA, USA). Met-1 cells were harvested when $70-80 \%$ confluent. Cells $\left(5 \times 10^{4}\right)$ in $50 \mu 1$ of DMEM were administered subcutaneously into the lower back of the mice. Tumors were measured two to three times per week. Tumor size $\left(\mathrm{mm}^{3}\right)$ was determined by measuring height, width and length of the tumors.

Body composition. We analyzed final body composition (\% body fat, \% lean body mass and BMD) by dual energy X-ray absorptiometry (DXA) using a GE Lunar Piximus II densitometer (Madison, WI, USA). Body fat levels (\%) of living animals were measured using an Echo Magnetic Resonance Imaging system (MRI; Echo Medical System, Houston, TX, USA).

Hormone analysis and blood chemistry. We measured hormone and ALT levels with the following ELISA kits: $17 \beta$-estradiol (IBL-America, Minneapolis, MN, USA), insulin-like growth factor 1 (IGF-1; R\&D Systems, Minneapolis, MN, USA), vascular endothelial growth factor (VEGF; R\&D Systems, Minneapolis, MN, USA) and alanine transaminase (ALT; Bioo Scientific, Austin, TX, USA). Mouse serum insulin and leptin levels were analyzed using a mouse adipokine Lincoplex kit (Linco Research, St. Louis, MO, USA). Alcohol concentration in the blood was detected using a NAD-ADH kit (Sigma, St. Louis, MO, USA). All experiments were performed following the manufacturer's instructions.

Western blot analysis. Whole-cell lysates were prepared from tumor tissue. Tissues were collected and snap-frozen in liquid N2. Frozen tissues were ground into a powder using a mortar and pestle, suspended in RIPA buffer (Sigma), containing protease and phosphatase inhibitors (Pierce, Rockford, IL, USA), and homogenized. Tissue extracts were centrifuged for $10 \mathrm{~min}$ at 10,000 RCF. Protein concentrations were measured using Bradford Protein Assay Reagent (Bio-Rad, Hercules, CA, USA). Lysates were resolved $(50 \mu \mathrm{g})$ on $10 \%$ Tris-acetate gels, and proteins were detected by Western blot analysis with the following antibodies: PI3K $(\mathrm{p} 85 \alpha)$, p-Akt ${ }^{\mathrm{Ser} 473}, \mathrm{Akt}, \beta$-actin, cleaved caspase-3 (Cell Signaling, Beverly, MA, USA) and PCNA (Santa Cruz Biotechnology, Santa Cruz, CA, USA). Blots were analyzed by densitometry and quantitated with ImageJ software (NIH, http://rsb.info.nih.gov/ij/).

Histology. Mouse tumor and liver tissues were harvested, fixed in $10 \%$ formalin for $24 \mathrm{~h}$ and transferred into $70 \%$ ethanol indefinitely. The samples were paraffin-embedded, sectioned and stained with hematoxylin and eosin (H\&E) by the Histology and Tissue Core at the University of Texas M.D. Anderson Cancer Center (Smithville, TX, USA).

Real-time $q P C R$. Tumor necrosis factor $\alpha(\mathrm{TNF}-\alpha)$ was measured in the liver. Total RNA was extracted from liver tissue 
A

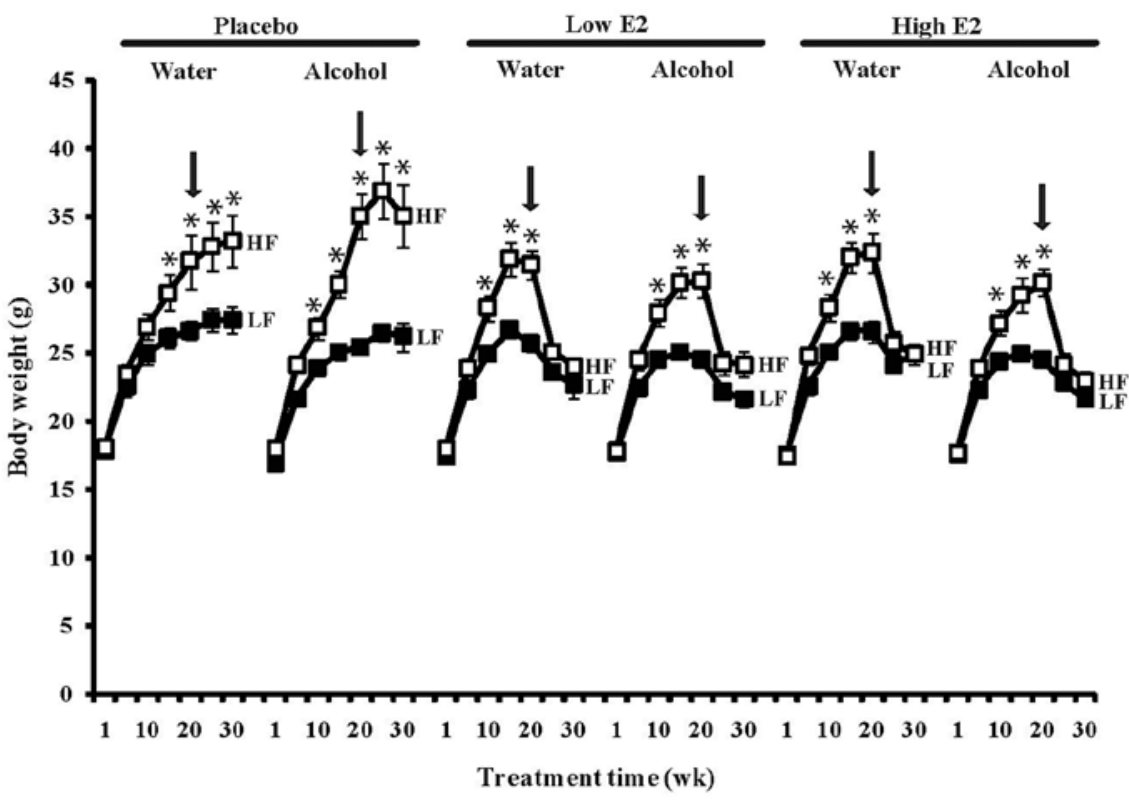

B
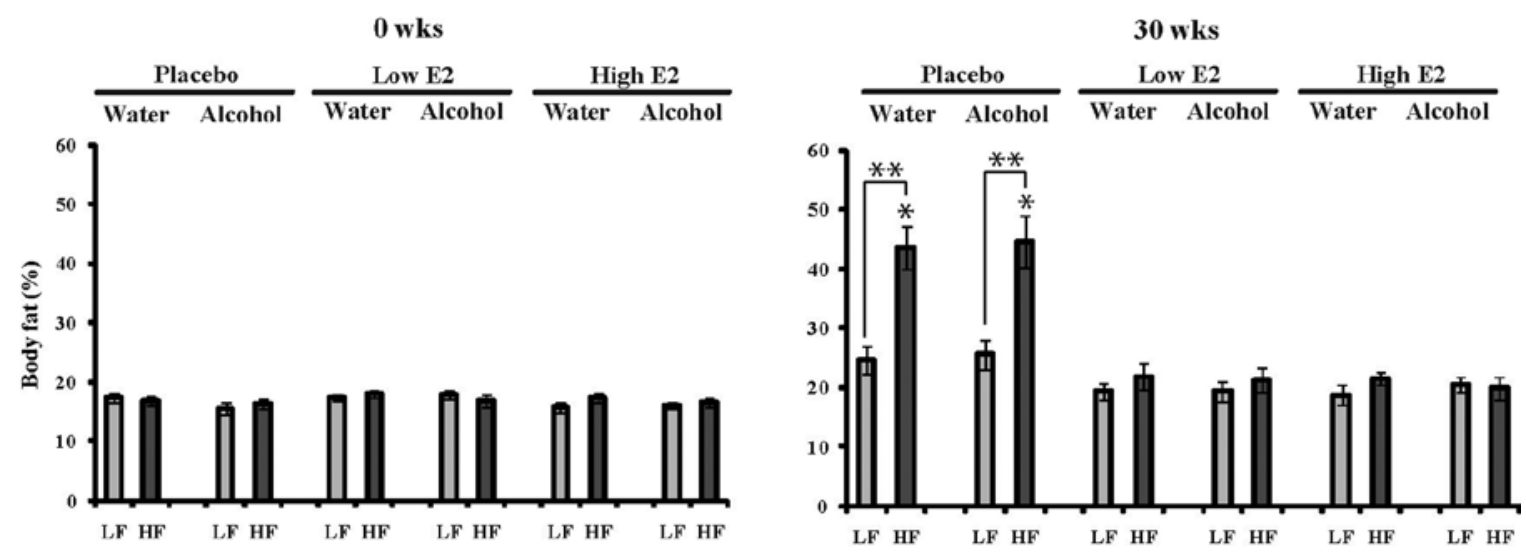

$\mathrm{C}$

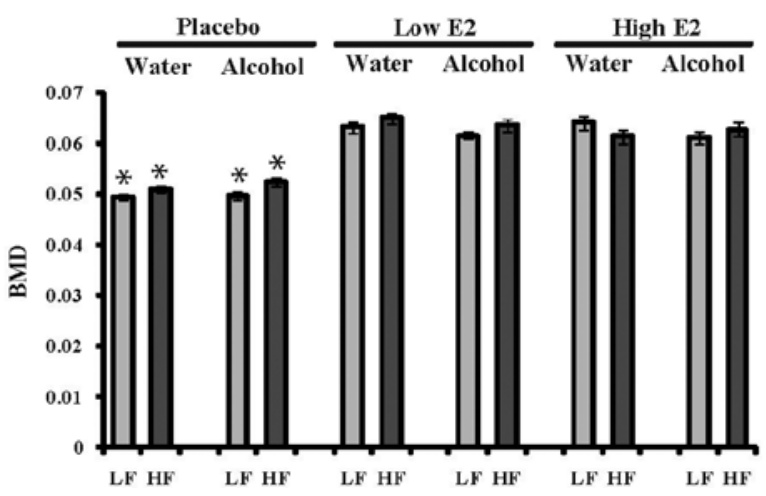

Figure 1. Body composition. (A) Summary of body weight change. OVX mice consuming water or $20 \%$ alcohol were provided with either an LF or HF diet. At week 19, they randomly received either a placebo or estrogen supplement (low and high), indicated by the arrow. *Significantly different between LF and HF mice $(\mathrm{p}<0.05)$. (B) Body fat comparison between baseline and the final time point. Graph shows the effects of diet, liquid and estrogen treatment. *Significantly different from estrogen groups within same diet and liquid groups $(\mathrm{p}<0.05),{ }^{* *}$ significantly different between LF and HF mice ( $\left.<<0.05\right)$. (C) BMD changes after estrogen supplementation. *Significantly different from estrogen treated mice $(\mathrm{p}<0.05)$. ( $\mathrm{n}=10 /$ group).

using a RNeasy mini kit (Qiagen, Hilden, Germany). The cDNA was synthesized from $1 \mu \mathrm{g}$ of total RNA using a High Capacity cDNA reverse transcription kit (Applied Biosystems, Foster City, CA). Real-time qPCR was performed on a Mastercycler Ep Realplex real-time qPCR thermocycler (Eppendorf, Hauppauge,
NY, USA). A SYBR-GreenER qPCR reagent (Invitrogen) was used in a $20-\mu 1$ total volume. All samples were done in triplicate. The relative expression levels of TNF- $\alpha$ were normalized to the average of the endogenous control gene, 18S ribosomal RNA. The difference was calculated using melting curve analysis. 
A
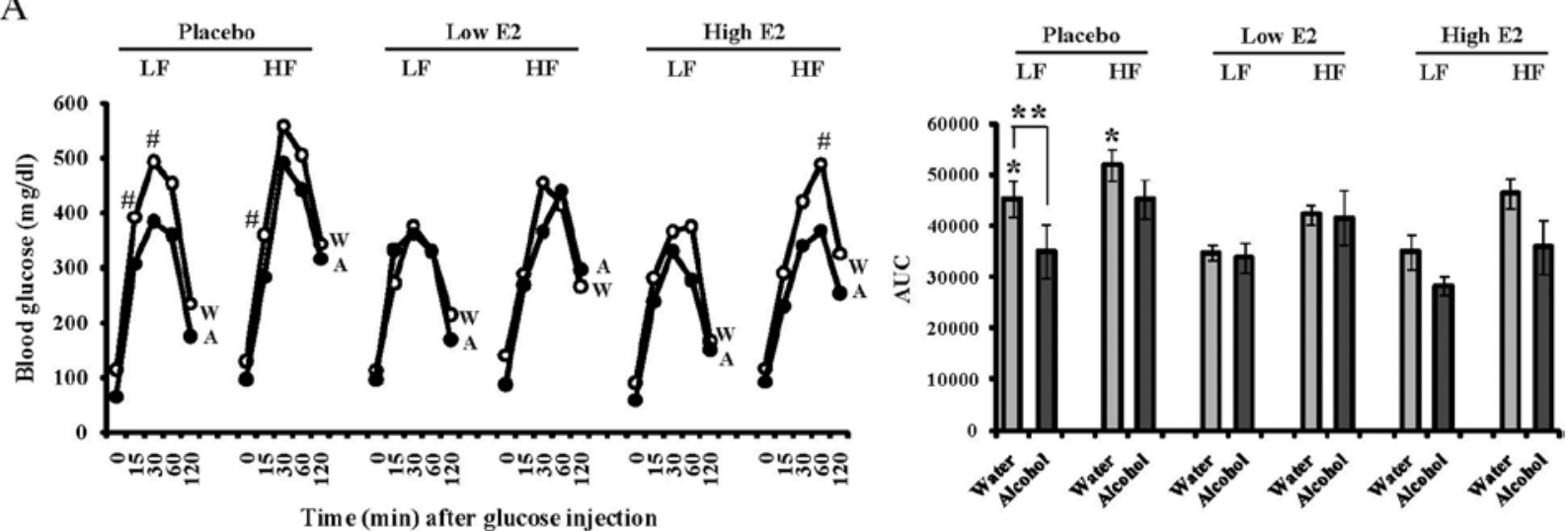

B
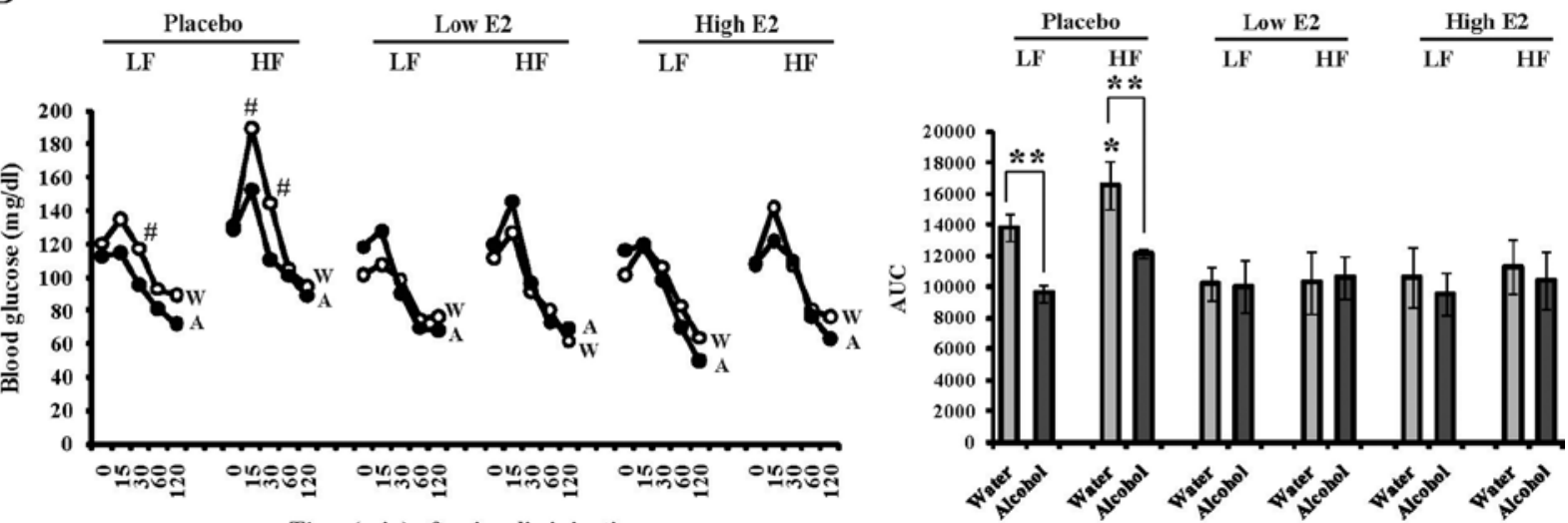

Figure 2. Alcohol and estrogen induced insulin sensitivity. (A) GTT; Alcohol and estrogen groups responded to the injected glucose more quickly than the water placebo group ( $\mathrm{n}=8$ /group). The graph to the right depicts the area under the curve (AUC). (B) ITT; Alcohol consumption and estrogen supplementation inhibited HF-induced insulin resistance as represented by the graph on the right ( $\mathrm{n}=8 /$ group). ${ }^{\#, * *}$ Significantly different between water and alcohol groups $(\mathrm{p}<0.05)$, * significantly different from estrogen-treated mice within same diet and liquid groups $(\mathrm{p}<0.05)$. W, water; A, alcohol.

We used the following primer pairs: $18 \mathrm{~S}$ forward 5'-GAG CTC ACC GGG TTG GTT TTG-3' and $18 \mathrm{~S}$ reverse 5'-TAC CTG GTT GAT CCT GCC AG-3', TNF- $\alpha$ forward 5'-CTC TTC AAG GGA CAA GGC TG-3' and TNF- $\alpha$ reverse 5'-CGG ACT CCG CAA AGT CTA AG-3'.

Statistical analysis. We analyzed all data (body composition, calorie intake, GTT, ITT, tumor growth, hormone levels and real-time $\mathrm{qPCR}$ ) by multivariate analysis of the variance and post hoc comparison of the means using Tukey's honestly significant difference. The results are shown as the mean \pm the standard error of the mean (SEM). We considered statistical significance at $\mathrm{p} \leq 0.05$. We used SPSS software package version 15.0 for Windows (SPSS Inc., Chicago, IL, USA) to make statistical comparisons.

\section{Results}

Alcohol, obesity and estrogen affect body composition. All mice had similar body weights $(17.6 \pm 0.1 \mathrm{~g})$ and body fat levels $(16.9 \pm 0.2 \%)$ at the beginning of the study after randomization ( $\mathrm{p}>0.05$; Fig. 1A and B). However, by the end of the study, the average final body weight and body fat was higher for HF compared to LF mice, as portrayed in Fig. 1A and B $(\mathrm{p}<0.05)$. Alcohol consumption did not alter either body weight or body fat in mice $(\mathrm{p}>0.05)$. Alcohol-consuming mice ingested slightly less food than water-consuming mice $(p>0.05)$ possibly because they received extra calories from the alcohol as shown in Table I. Consumption of $20 \%$ alcohol provided $1.42 \mathrm{kcal} / \mathrm{g}$ and elevated blood alcohol levels to $38-54 \mathrm{mg} / \mathrm{dl}$ : levels that have been shown to increase breast cancer risk in women $(2,43,44)$. The only statistically significant difference in body weight and body fat occurred after estrogen treatment (week 19 on the study), regardless of alcohol consumption $(\mathrm{p}<0.01)$. Both doses of estrogen caused a significant decrease in body weight and fat compared to placebo groups. Fig. 1C shows estrogen also increased BMD in both low and high E2 treatment groups $(\mathrm{p}<0.05)$. Collectively, the decrease in body weight and increase in BMD indicated the effectiveness of the estrogen treatment. No difference in body composition was observed between the low and high E2 treatment groups.

Alcohol, obesity and estrogen modulate insulin sensitivity. As expected, results from the GTT indicated that obese animals in both the water- and alcohol-consuming groups were more insulin resistant than control animals, as depicted in Fig. 2A $(\mathrm{p}<0.05)$. However, the alcohol-consuming mice cleared blood glucose faster than water consuming mice $(\mathrm{p}<0.05)$. Both doses of estrogen also improved glucose clearance compared to placebo, especially in HF mice $(\mathrm{p}<0.05)$. There was no 


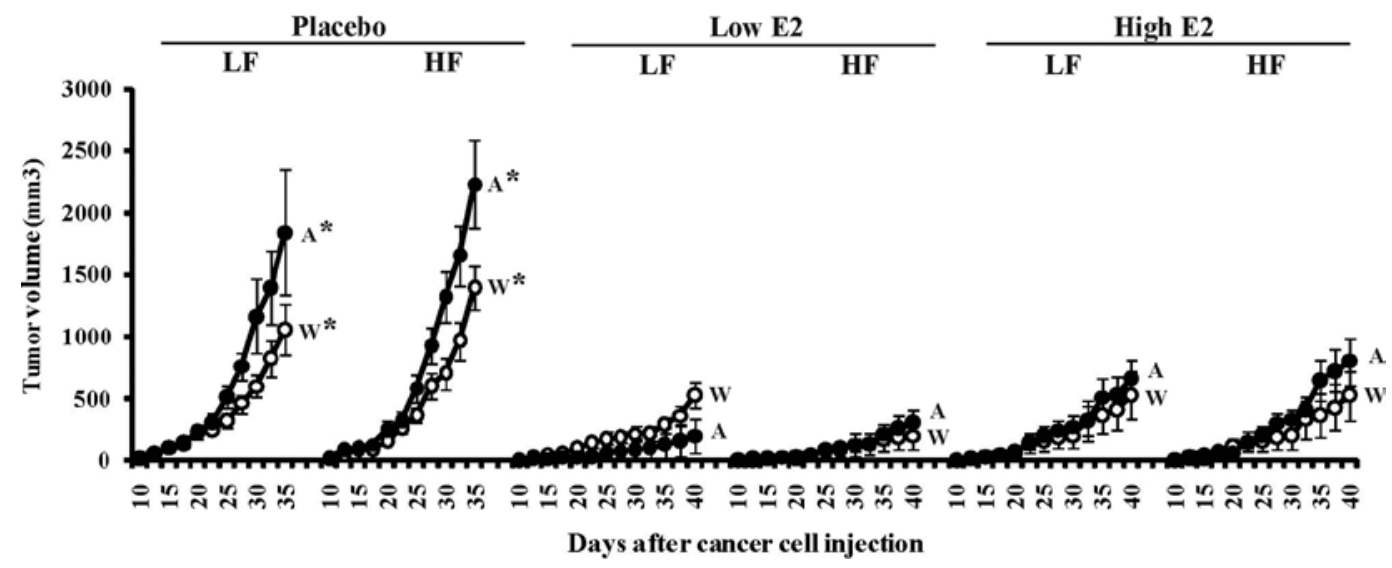

Figure 3. Influence of alcohol, obesity and estrogen on mammary tumor growth. Tumor volume was increased in alcohol consuming mice compared to control mice. Estrogen treatment (low and high) inhibited tumor growth ( $\mathrm{n}=10$ /group). Tumor size was recorded every two to three days. Graph displays tumor growth every five days. "Significantly different from estrogen-treated mice within the same diet and liquid groups ( $<<0.05)$. Abbreviations: W, water; A, alcohol.

Table I. Comparison of final calorie intake and blood alcohol concentration (BAC) in mice.

\begin{tabular}{|c|c|c|c|c|c|c|c|c|c|c|c|c|}
\hline & \multicolumn{4}{|c|}{ Placebo } & \multicolumn{4}{|c|}{ Low E2 } & \multicolumn{4}{|c|}{ High E2 } \\
\hline & \multicolumn{2}{|c|}{ Water } & \multicolumn{2}{|c|}{ Alcohol } & \multicolumn{2}{|c|}{ Water } & \multicolumn{2}{|c|}{ Alcohol } & \multicolumn{2}{|c|}{ Water } & \multicolumn{2}{|c|}{ Alcohol } \\
\hline & $\mathrm{LF}$ & $\mathrm{HF}$ & $\mathrm{LF}$ & $\mathrm{HF}$ & $\mathrm{LF}$ & $\mathrm{HF}$ & $\mathrm{LF}$ & $\mathrm{HF}$ & LF & $\mathrm{HF}$ & $\mathrm{LF}$ & $\mathrm{HF}$ \\
\hline Food (kcal) & $9.6 \pm 0.4$ & $11.2 \pm 0.9$ & $7.9 \pm 0.7$ & $10.5 \pm 1.0$ & $10.4 \pm 0.8$ & $9.4 \pm 0.2$ & $8.2 \pm 0.3$ & $8.3 \pm 0.5$ & $10.4 \pm 0.8$ & $9.5 \pm 0.4$ & $7.4 \pm 0.2$ & $9.8 \pm 1.8$ \\
\hline Alcohol (kcal) & - & - & $2.5 \pm 0.1$ & $2.3 \pm 0.2$ & - & - & $2.2 \pm 0.1$ & $2.1 \pm 0.2$ & - & - & $2.3 \pm 0.1$ & $2.0 \pm 0.2$ \\
\hline Total (kcal) & $9.6 \pm 0.4$ & $11.2 \pm 0.9$ & $10.4 \pm 0.4$ & $12.9 \pm 1.0$ & $10.4 \pm 0.8$ & $9.4 \pm 0.2$ & $10.4 \pm 0.4$ & $10.8 \pm 0.6$ & $10.4 \pm 0.8$ & $9.5 \pm 0.4$ & $9.7 \pm 0.2$ & $11.8 \pm 1.8$ \\
\hline $\mathrm{BAC}(\mathrm{mg} / \mathrm{dl})^{\mathrm{a}}$ & $0.0 \pm 0.0$ & $0.0 \pm 0.0$ & $37.9 \pm 0.3$ & $54.4 \pm 4.8$ & $0.0 \pm 0.0$ & $0.1 \pm 0.0$ & $38.4 \pm 0.4$ & $42.1 \pm 2.0$ & $0.0 \pm 0.0$ & $0.1 \pm 0.0$ & $38.6 \pm 0.3$ & $39.0 \pm 0.2$ \\
\hline
\end{tabular}

Values are presented as the mean \pm SEM ( $n=10$ /group). ${ }^{a}$ Significantly different between water and alcohol groups in the same diet (LF or HF) and treatment (E2 or placebo) categories.

difference between low and high E2 groups ( $\mathrm{p}>0.05)$. In Fig. 2B, results from the ITT illustrated that HF-diet fed mice responded to exogenous insulin more slowly than LF-diet fed mice $(\mathrm{p}<0.05)$, indicating insulin resistance. However, alcohol promoted glucose clearance in HF mice compared to mice on water $(\mathrm{p}<0.05)$. Insulin sensitivity was increased in animals receiving low and high $\mathrm{E} 2$ treatment $(\mathrm{p}<0.05)$; this effect was not altered by alcohol consumption or dose of E2 ( $p>0.05)$.

Alcohol, obesity and estrogen affect mammary tumorigenesis. Mice consuming the HF diet developed larger tumors than LF fed mice, as depicted in Fig. 3. Alcohol ingestion increased the final tumor volume by $\sim 1.6$-fold compared to water consumption, especially in $\mathrm{HF}$ mice $(\mathrm{p}<0.05)$. Estrogen treatment suppressed tumor growth regardless of diet intake, alcohol consumption and estrogen dose compared to placebo $(\mathrm{p}<0.05)$. Despite the estrogen-induced tumor inhibition, mice receiving high E2 treatment tended to have slightly larger tumors than mice treated with the low dose of E2 ( $>0.05)$. Similarly, mice consuming alcohol and receiving the high E2 supplement had somewhat larger tumors than the water group $(\mathrm{p}>0.05)$.
PI3K/Akt signaling pathway in response to alcohol, obesity and estrogen. The regulatory subunit of PI3K (p85 $\alpha$ ) was not affected by alcohol, obesity (HF) or estrogen treatment, as depicted in Fig. 4. Alcohol consumption and obesity resulted in increased expression of phosphorylated Akt at Serine 473, which is positively associated with cell proliferation, survival and invasion (44). However, estrogen supplementation reduced the Akt phosphorylation induced by both HF diet and alcohol consumption. The expression level of cleaved caspase-3, a key factor in apoptosis, was decreased with obesity and alcohol consumption. An additive decrease in apoptosis levels were observed in obese mice receiving alcohol. Cell proliferation was not altered by body weight, alcohol or estrogen as measured by PCNA expression.

Alteration of growth factors by alcohol, obesity and estrogen. As anticipated, exogenous estrogen supplementation dramatically elevated circulating estrogen levels in mice compared to pre-E2 treatment, as portrayed in Fig. 5A ( $p<0.001)$. In addition, mice receiving the high dose of E2 had higher serum estrogen levels than mice receiving the low E2 supplement $(\mathrm{p}<0.05)$. The expression of leptin was directly proportional to 
A

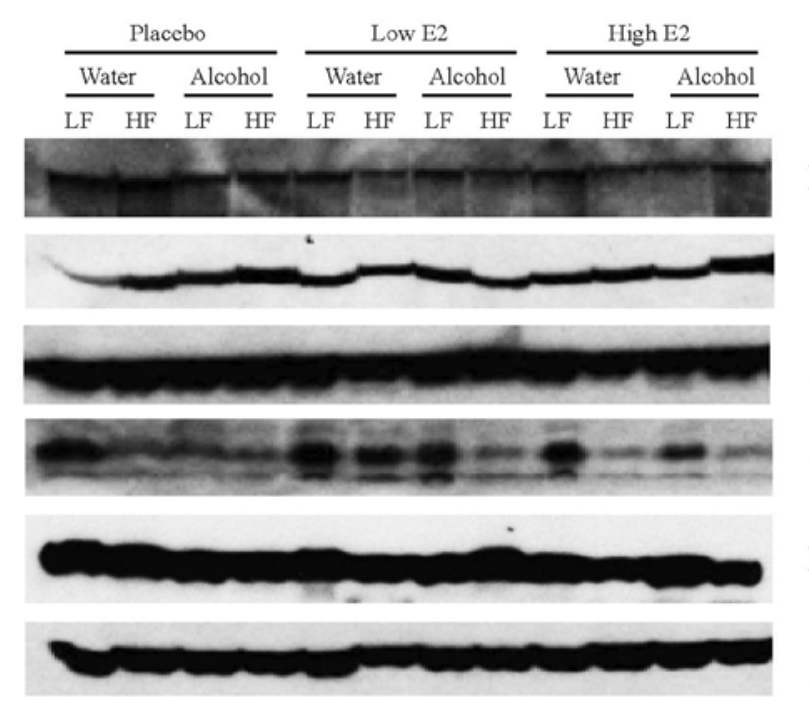

PI3K (p85 $\alpha)$

pAkt (ser473)

Akt

Cleaved caspase-3

PCNA

$\beta-$ actin

B
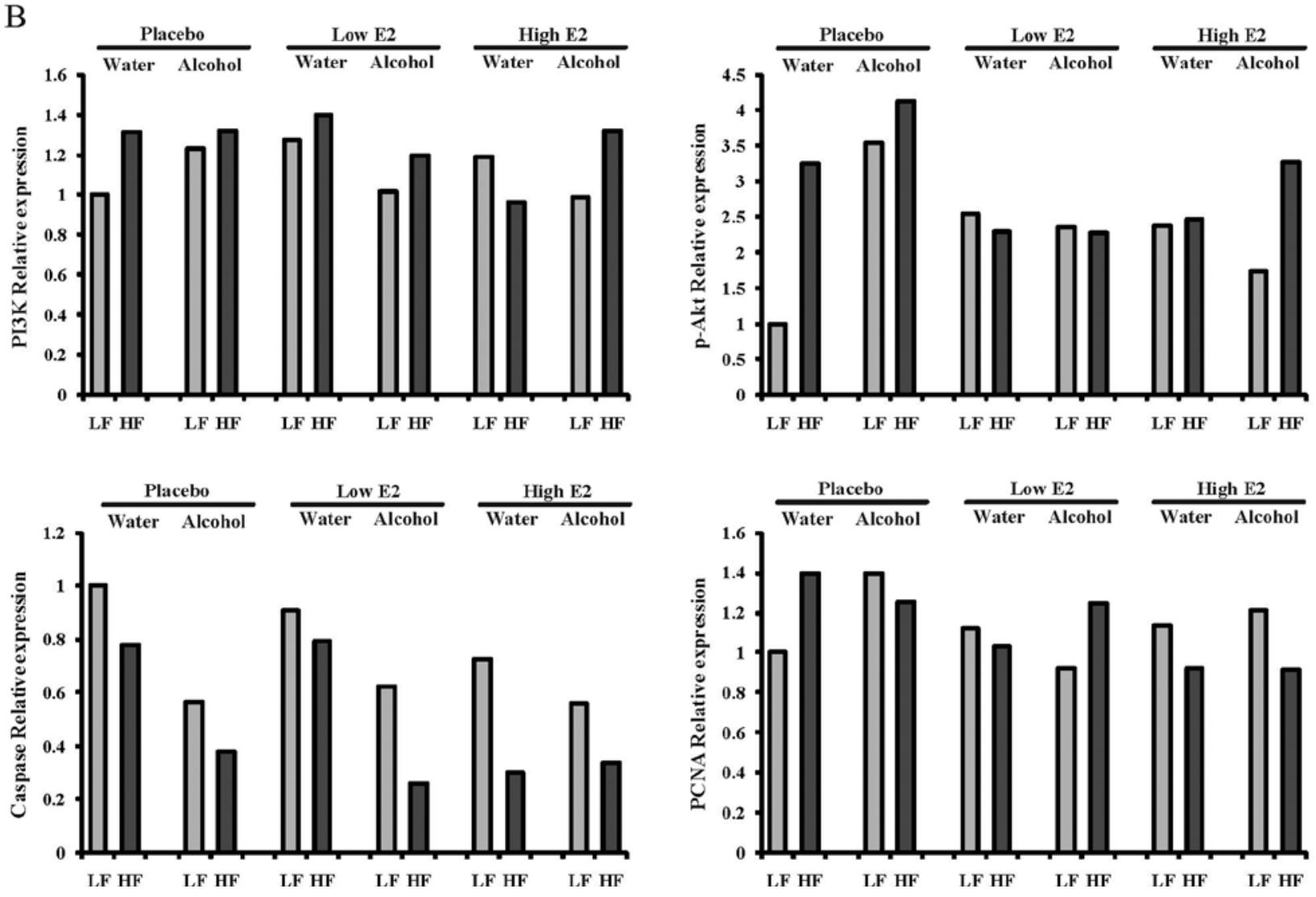

Figure 4. The effect of alcohol, obesity and estrogen on protein expression. Survival signaling. Alcohol and obesity induced Akt phosphorylation and reduced cleaved casepase-3 expression. Graphs along the bottom depict the quantitation of the Western blot analysis. These blots are representative of 3 mice per group.

body fat levels as shown in Fig. 5B, for both pre and post-E2 groups $(\mathrm{p}<0.05)$. This was also reflected after estrogen treatment, as a decrease in serum leptin levels accompanied the drastic reduction in body fat levels. Both doses of estrogen resulted in a significant reduction in leptin levels $(\mathrm{p}<0.001)$. Compared to the water group, alcohol stimulated leptin expression in obese mice. Expression of the pro-angiogenic factor VEGF was induced by both alcohol consumption and obesity for placebo and estrogen treatment groups (Fig. 5C).
Moreover, exogenous estrogen reduced serum VEGF levels compared to placebo $(\mathrm{p}<0.05)$. Serum insulin and IGF-1 levels were increased in the obese phenotype and greatly decreased after estrogen treatment (Fig. 5D and E; p<0.05). Alcohol did not affect the expression of serum insulin and IGF-1 compared to control ( $\mathrm{p}>0.05)$.

Alcohol, obesity and estrogen regulate liver histopathology. Fig. 6A depicts changes in liver histopathology after alcohol 
A

Pre-E2 treatment
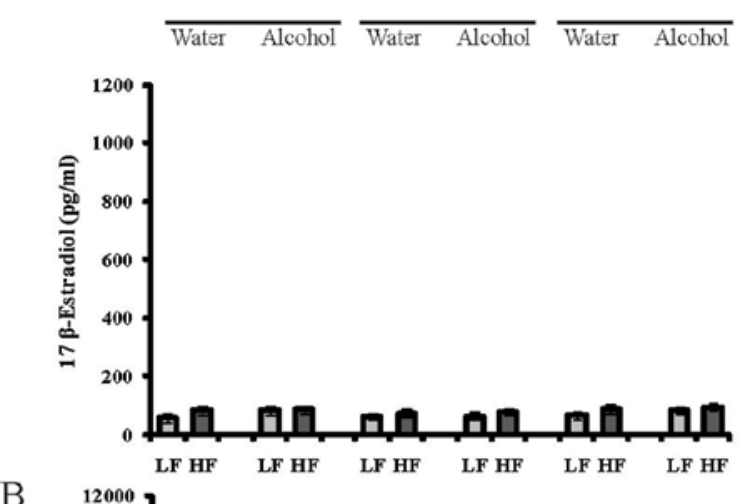

B

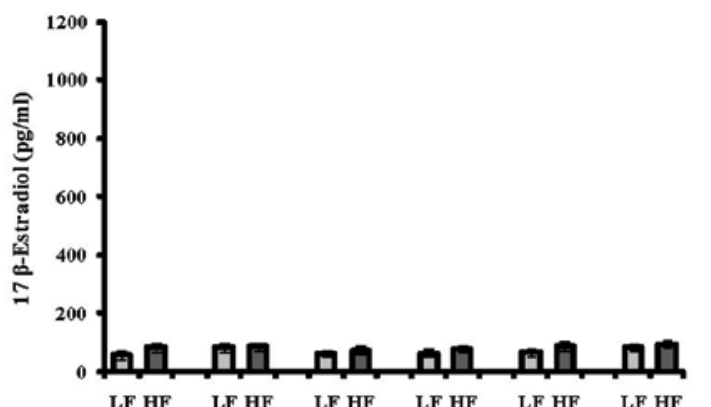

C
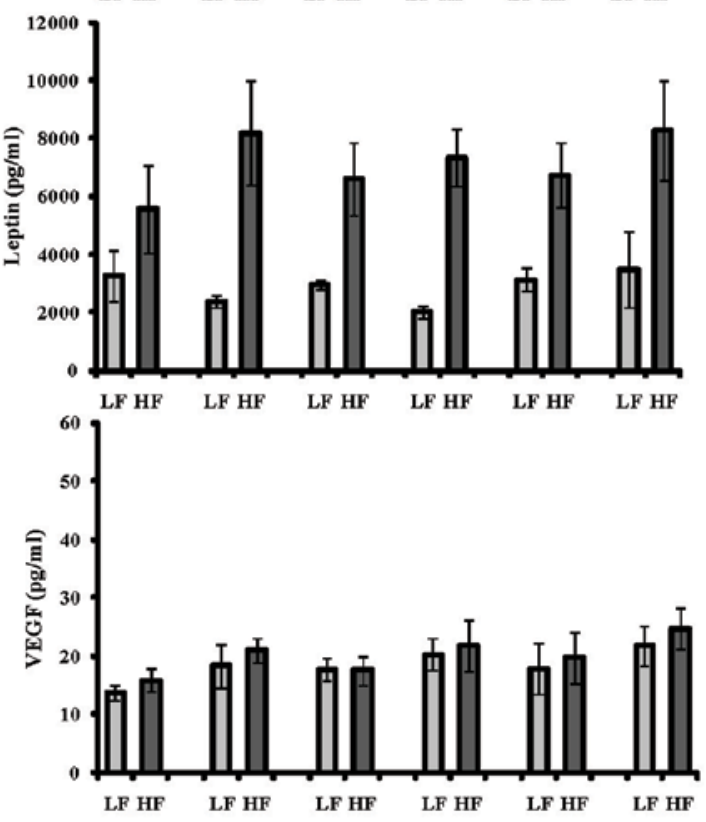

$\mathrm{D}$

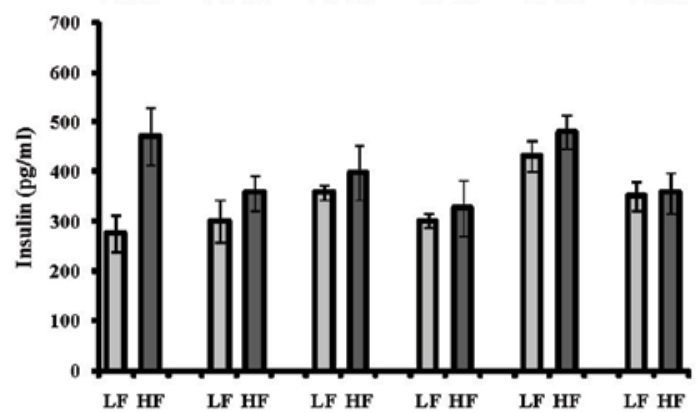

$\mathrm{E}$

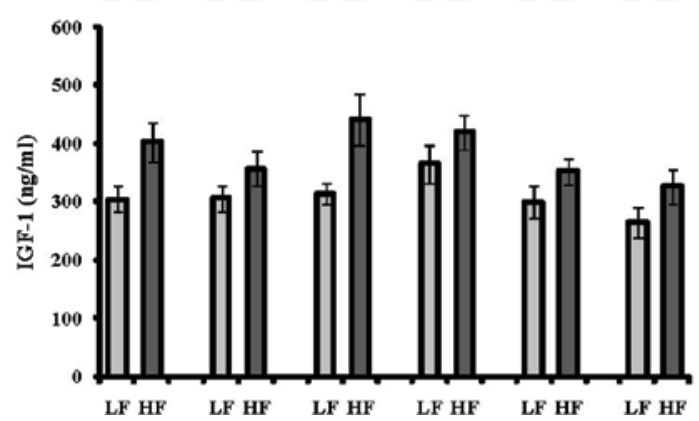

Post-E2 treatment

$\frac{\text { Placebo }}{\text { Water Alcohol }} \frac{\text { Low E2 }}{\text { Water Alcohol }} \frac{\text { High E2 }}{\text { Water Alcohol }}$
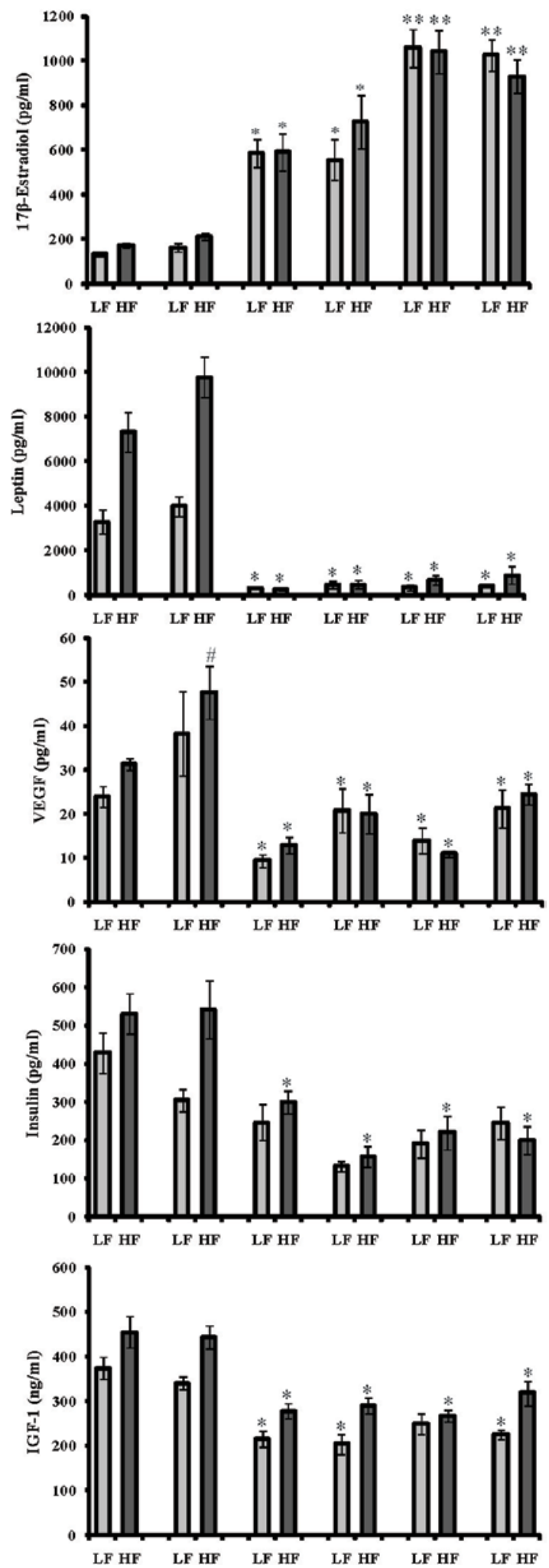

Figure 5. Alcohol, obesity and estrogen modulate hormone levels. Circulating hormone levels were measured in serum from pre- (week 18) and post-estrogen treatment (week 30). (A) Estrogen-supplemented mice had low estrogen levels pre-E2 treatment. Estrogen levels were significantly increased after estrogen pellets (low and high) were implanted as seen in the post-E2 groups. (B) The HF mice had higher leptin levels than LF mice pre-E2 treatment. Estrogen treatment dramatically reduced leptin levels in both LF and HF mice. (C) Pro-angiogenic factor, VEGF, was induced by alcohol consumption but reduced by estrogen treatment. (D) Serum-insulin levels were increased after HF diet, but were decreased after estrogen treatment. (E) IGF-1, a growth hormone, levels were decreased by estrogen treatment and increased by obesity ( $\mathrm{n}=7$ /group for all assays). "Significantly different from placebo within same diet and liquid groups $(\mathrm{p}<0.05),{ }^{* *}$ significantly different from placebo and low E2 treatment within same diet and liquid groups in post-E2 treatment $(\mathrm{p}<0.05),{ }^{\#}$ significantly different between water- and alcohol-consuming mice in HF mice $(\mathrm{p}<0.05)$. 
A

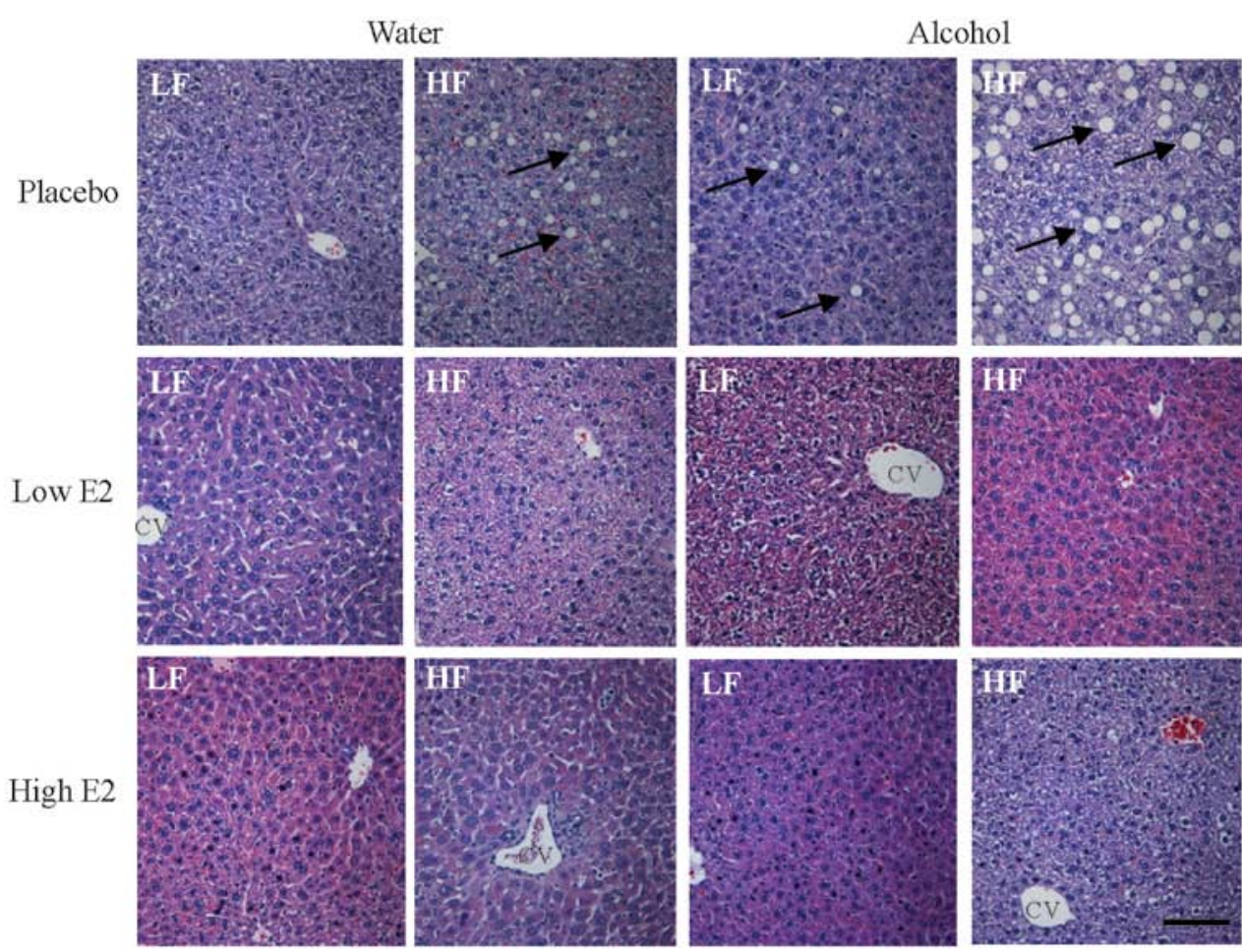

B

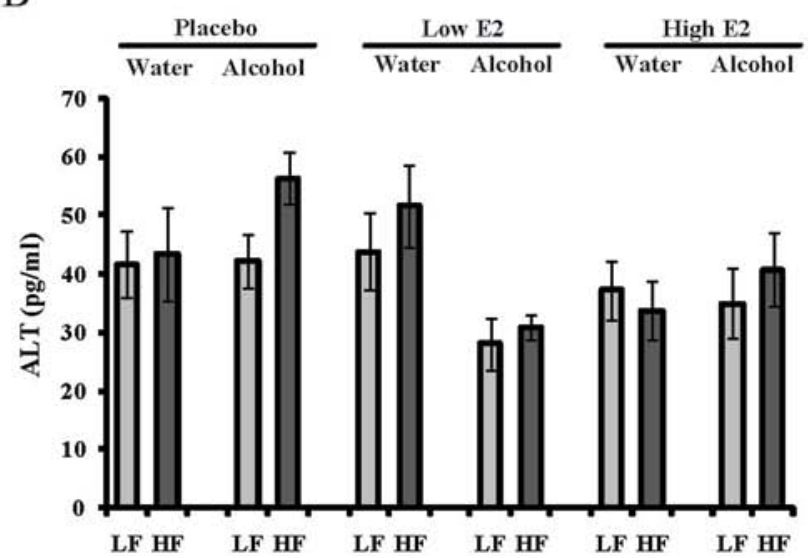

$\mathrm{C}$

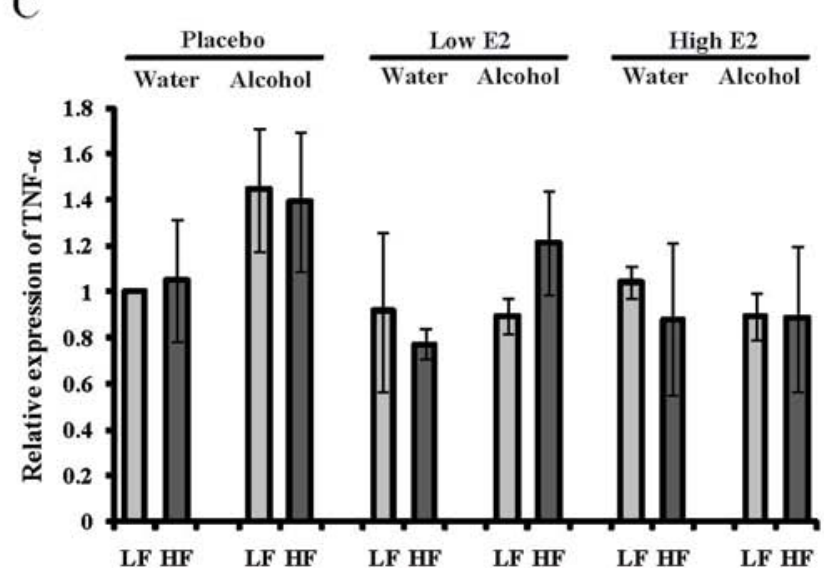

Figure 6. Liver histopathology. (A) The liver H\&E data showed alcohol and HF diet increased hepatic steatosis while estrogen treatment decreased this effect ( $\mathrm{n}=5$ /group). The images were captured at x20 magnification; $100 \mu \mathrm{m}$ bar. The arrow indicates hepatic fat globules. CV, central vein. (B) ELISA of serum ALT ( $n=7 /$ group). (C) TNF- $\alpha$ qPCR of liver tissue ( $n=4 /$ group). Estrogen had no effect on ALT or TNF- $\alpha$ levels ( $p>0.05$ ).

consumption, obesity and estrogen supplementation. Both alcohol and obesity are well known to induce hepatic steatosis (45). Our data support the literature. Obesity induced hepatic steatosis as shown by the fat globules in the H\&E staining. Alcohol consumption also promoted this effect. However, hepatic steatosis, especially in mice receiving alcohol, was reduced by estrogen treatment regardless of dose. Even obese mice consuming alcohol with extreme steatosis showed a dramatic decrease in hepatic steatosis after receiving either dose of estrogen. Next, we measured the expression levels of ALT and TNF- $\alpha$, hepatic inflammatory factors known to be involved in hepatic steatosis. The results are portrayed in Fig. 6B and C. Alcohol consumption slightly increased ALT and TNF- $\alpha$ expression compared to the control, but the difference was not significant $(\mathrm{p}>0.05)$. Neither dose of exogenous estrogen had a significant effect on TNF- $\alpha$ nor ALT levels in either the water or alcohol groups ( $>0.05)$. Moreover, expression was not affected by body weight.

\section{Discussion}

Postmenopausal women ranging from lean to obese have varying amounts of adipose tissue. Some of whom consume alcohol and receive estrogen to stop the consequences of menopause. It is unclear whether the effects of alcohol on breast cancer development are modified by body weight or exogenous estrogen. To this end, low-fat (overweight) and high-fat (obese) mice consuming water or alcohol were implanted with placebo or estrogen pellets before being injected subcutaneously with Met-1 breast cancer cells. Here, we show an adiposity- 
dependent increase in tumor growth and a decrease in insulin sensitivity. We examine the contribution of alcohol, obesity and exogenous estrogen on mammary tumor growth via the PI3K/Akt signaling pathway and adiposity in mice.

Alcohol acts in a dichotomous manner and elicits an advantageous phenotype of increased insulin sensitivity and a deleterious phenotype of enhanced tumorigenesis. The effects of alcohol were modified by body weight and estrogen administration. Obese mice developed the largest tumors and were more insulin resistant than overweight mice. Alcohol consumption further increased tumor size for both overweight and obese mice. In contrast, both doses of supplemental estrogen suppressed tumor growth, triggered insulin sensitivity and induced loss of body fat in both obese and overweight mice. We questioned how alcohol can have such a paradoxical effect. Alcohol has been shown to accelerate mammary tumor growth rate in mice (46) and increase the metastatic potential of breast cancer cells in a dose-dependent manner in vitro $(5,47)$. We reasoned that alcohol could make mammary cancer cells more susceptible to hormones, which would result in primary tumor growth and/or metastasis, while simultaneously increase the hormone responsiveness of tissues and preventing insulin resistance and type- 2 diabetes by increasing insulin secretion to stimulate insulin sensitivity (48). Huang et al showed that alcohol triggered the pancreas to secrete insulin resulting in increased insulin sensitivity in mice (48). Our studies support this idea as we noted an increase in serum insulin levels in mice drinking alcohol compared to water, although the difference was not statistically significant.

In premenopausal women, estrogen, a steroid hormone, is generated primarily by the ovaries. After menopause, however, peripheral tissues (adipose tissue) produce estrogen through the conversion of androgen to estrogen by aromatase (29). Aromatase is found in white adipose tissue (49) and therefore, postmenopausal women who are obese have higher levels of estrogen than lean premenopausal women as they have more fat (20). High-estrogen levels are associated with increased breast cancer (29). Intriguingly, we observed that two different doses of estrogen actually had a negative effect on tumor growth. Tumorigenesis was decreased by estrogen regardless of adiposity and whether the mice consumed alcohol or water. Data from the current study disputes the present dogma regarding the role of estrogen in tumor promotion. In support, Nkhata et al observed reduced tumor growth in obese mice injected with T47-D human breast cancer cells after estrogen pellet implantation compared to placebo (50). It is possible that the effects of estrogen on tumor growth are due to differences between exogenous and endogenous estrogen. Sham ovariectomized mice in this study developed significantly larger tumors than mice receiving exogenous estrogen (data not shown). This is unlikely, however, as both endogenous and exogenous estrogen have been shown to be risk factors for breast cancer (51-53). This is supported by numerous epidemiology studies portraying the positive association between hormone replacement therapy and breast cancer $(54,55)$. Additionally, the negative effect of estrogen on tumor development may be due to the timing of estrogen treatment. The Woman's Health Initiative found hormone therapy should be initiated five or more years after menopause in order to reduce breast cancer risk (56).
Observed increases in serum insulin, IGF-1, leptin and VEGF were directly proportional to body weight. Hormones, insulin resistance and angiogenesis have all been shown to be players in breast tumorigenesis $(57,58)$. Although obesity and alcohol increased serum levels of insulin and IGF-1, no such cooperative effect between alcohol and obesity was observed. As a result, we focused on leptin and VEGF as potential contributors to tumor growth. Not only was leptin increased by adiposity and alcohol consumption, but an additive increase was noted in the presence of both factors. A high level of circulating leptin is associated with breast cancer development $(2,18,37,59)$. Moreover, leptin has been shown to enhance the growth and invasive potential of breast cancer cells in tissue culture $(59,60)$. Leptin may promote breast carcinogenesis by regulating aromatase activity and increasing estrogen levels where the breast cancer cells are located in the mammary gland (37). Adiposity, alcohol and a cooperation of these two factors also increased VEGF levels. VEGF is a key factor in angiogenesis, a physiological process essential for tumor growth and metastasis $(61,62)$. Our results were further supported after estrogen administration as tumor growth was decreased along with serum leptin and VEGF levels. These findings were unexpected since estrogen has been shown to increase serum levels of leptin and VEGF in some studies $(63,64)$. In our study, body weight and body-fat levels drastically decreased along with a concomitant decrease in serum leptin and VEGF after estrogen supplementation. This could account for the discrepancy on the effect of estrogen on insulin and VEGF observed by others. Mice in all groups consumed similar amounts of calories showing the effect was due to estrogen and not a change in calorie consumption.

Estrogen may affect mammary tumorigenesis via the PI3K/Akt signaling pathway (65-67). Estrogen has been shown to influence pro-apoptotic pathways (68-71). Zhang et al demonstrated that PI3K/Akt signaling could be inhibited by estrogen and induce apoptosis of cancer cells (68). Breast cancer cells that have been long-term deprived of estrogen can undergo apoptosis after estrogen treatment $(72,73)$. Obesity and alcohol can also alter PI3K/Akt signaling. A multitude of hormones/cytokines (insulin, leptin, IL-6) that increased with obesity have been shown to activate the PI3K/Akt signaling pathway (74). Similarly, moderate alcohol consumption increases Akt expression (14). In the present study, we demonstrated enhanced Akt (S473) phosphorylation in obese mice, which was further increased with alcohol treatment. We also observed a decrease in cleaved caspase-3 expression under the same conditions, indicating reduced apoptosis. Phospho-Akt levels were reduced after estrogen pellet implantation in obese mice. These data suggest a putative role for the PI3K/ Akt pathway and pro-apoptotic pathways in tumor growth regulation.

Our results show that alcohol consumption promoted insulin sensitivity and increased Met-1 mammary tumor growth in obese mice without affecting body weight or body fat levels. Alcohol consumption and obesity caused hepatic steatosis in mice while exogenous estrogen improved this effect. Exogenous estrogen treatment led to a dramatic loss of body weight and insulin sensitivity which could be responsible for the observed inhibition of tumor growth in obese mice consuming alcohol. Furthermore, estrogen-treated mice 
showed a reduction in adiposity-related hormone levels along with decreased PI3K/Akt signaling. Our studies are the first to show estrogen functions as a protective factor against the effects of alcohol and obesity on fatty liver development and mammary tumorigenesis.

\section{Acknowledgements}

This work was supported by grants ACS RSG CNE-113703 (NPN), NCI 1K22CA127519-01A1 (NPN), NIEHS National Institutes of Health ES09145, and National Institute of Environmental Health Sciences Center ES007784.

\section{References}

1. American Cancer Society. Breast Cancer Facts \& Figures 20092010. Atlanta: American Cancer Society, Inc.

2. Smith-Warner SA, Spiegelman D, Yaun SS, et al: Alcohol and breast cancer in women: a pooled analysis of cohort studies JAMA 279: 535-540, 1998.

3. Berstad P, Ma H, Bernstein L and Ursin G: Alcohol intake and breast cancer risk among young women. Breast Cancer Res Treat 108: 113-120, 2008

4. Hamajima N, Hirose K, Tajima K, et al: Alcohol, tobacco and breast cancer - collaborative reanalysis of individual data from 53 epidemiological studies, including 58,515 women with breast cancer and 95,067 women without the disease. Br J Cancer 87: 1234-1245, 2002.

5. Singletary K: Ethanol and experimental breast cancer: a review. Alcohol Clin Exp Res 21: 334-339, 1997.

6. Vaeth PA and Satariano WA: Alcohol consumption and breast cancer stage at diagnosis. Alcohol Clin Exp Res 22: 928-934, 1998

7. Luo J: Role of matrix metalloproteinase-2 in ethanol-induced invasion by breast cancer cells. J Gastroenterol Hepatol 21 (Suppl 3): S65-S68, 2006.

8. Singletary KW and Gapstur SM: Alcohol and breast cancer: review of epidemiologic and experimental evidence and potential mechanisms. JAMA 286: 2143-2151, 2001.

9. Hennig M, Yip-Schneider MT, Klein P, et al: Ethanol-TGFalphaMEK signaling promotes growth of human hepatocellular carcinoma. J Surg Res 154: 187-195, 2009.

10. Stoll BA: Alcohol intake and late-stage promotion of breast cancer. Eur J Cancer 35: 1653-1658, 1999.

11. Dumitrescu RG and Shields PG: The etiology of alcohol-induced breast cancer. Alcohol 35: 213-225, 2005.

12. Tsai EM, Wang SC, Lee JN and Hung MC: Akt activation by estrogen in estrogen receptor-negative breast cancer cells. Cancer Res 61: 8390-8392, 2001.

13. Zhou HZ, Karliner JS and Gray MO: Moderate alcohol consumption induces sustained cardiac protection by activating PKC-epsilon and Akt. Am J Physiol Heart Circ Physiol 283: H165-H174, 2002.

14. Sozio M and Crabb DW: Alcohol and lipid metabolism. Am J Physiol Endocrinol Metab 295: E10-E16, 2008.

15. You M and Crabb DW: Recent advances in alcoholic liver disease II. Minireview: molecular mechanisms of alcoholic fatty liver. Am J Physiol Gastrointest Liver Physiol 287: G1-G6, 2004.

16. McTiernan A: Behavioral risk factors in breast cancer: can risk be modified? Oncologist 8: 326-334, 2003.

17. Calle EE, Rodriguez C, Walker-Thurmond $\mathrm{K}$ and Thun MJ: Overweight, obesity, and mortality from cancer in a prospectively studied cohort of US adults. N Engl J Med 348: 1625-1638, 2003.

18. Bianchini F, Kaaks R and Vainio H: Overweight, obesity, and cancer risk. Lancet Oncol 3: 565-574, 2002.

19. Petrelli JM, Calle EE, Rodriguez C and Thun MJ: Body mass index, height, and postmenopausal breast cancer mortality in a prospective cohort of US women. Cancer Causes Control 13: 325-332, 2002

20. Modugno F, Kip KE, Cochrane B, et al: Obesity, hormone therapy, estrogen metabolism and risk of postmenopausal breast cancer. Int J Cancer 118: 1292-1301, 2006.

21. Brakenhielm E, Veitonmaki N, Cao R, et al: Adiponectin-induced antiangiogenesis and antitumor activity involve caspase-mediated endothelial cell apoptosis. Proc Natl Acad Sci USA 101: 2476-2481, 2004.
22. Carmichael AR: Obesity as a risk factor for development and poor prognosis of breast cancer. BJOG 113: 1160-1166, 2006.

23. Nam SY, Lee EJ, Kim KR, et al: Effect of obesity on total and free insulin-like growth factor (IGF)-1, and their relationship to IGF-binding protein (BP)-1, IGFBP-2, IGFBP-3, insulin, and growth hormone. Int J Obes Relat Metab Disord 21: 355-359, 1997.

24. Novosyadlyy R, Lann DE, Vijayakumar A, et al: Insulin-mediated acceleration of breast cancer development and progression in a nonobese model of type 2 diabetes. Cancer Res 70: 741-751, 2010.

25. Dixon JB, Bhathal PS and O'Brien PE: Nonalcoholic fatty liver disease: predictors of nonalcoholic steatohepatitis and liver fibrosis in the severely obese. Gastroenterology 121: 91-100, 2001.

26. Matteoni CA, Younossi ZM, Gramlich T, Boparai N, Liu YC and McCullough AJ: Nonalcoholic fatty liver disease: a spectrum of clinical and pathological severity. Gastroenterology 116: 1413-1419, 1999.

27. Ludwig J, Viggiano TR, McGill DB and Oh BJ: Nonalcoholic steatohepatitis: Mayo Clinic experiences with a hitherto unnamed disease. Mayo Clin Proc 55: 434-438, 1980.

28. Santen RJ, Brodie H, Simpson ER, Siiteri PK and Brodie A: History of aromatase: saga of an important biological mediator and therapeutic target. Endocr Rev 30: 343-375, 2009.

29. Suzuki R, Ye W, Rylander-Rudqvist T, Saji S, Colditz GA and Wolk A: Alcohol and postmenopausal breast cancer risk defined by estrogen and progesterone receptor status: a prospective cohort study. J Natl Cancer Inst 97: 1601-1608, 2005.

30. Etique N, Chardard D, Chesnel A, Merlin JL, Flament S and Grillier-Vuissoz I: Ethanol stimulates proliferation, ERalpha and aromatase expression in MCF-7 human breast cancer cells. Int J Mol Med 13: 149-155, 2004.

31. Li CI, Chlebowski RT, Freiberg M, et al: Alcohol consumption and risk of postmenopausal breast cancer by subtype: the women's health initiative observational study. J Natl Cancer Inst 102: 1422-1431, 2010.

32. Chen WY, Colditz GA, Rosner B, et al: Use of postmenopausal hormones, alcohol, and risk for invasive breast cancer. Ann Intern Med 137: 798-804, 2002.

33. Gapstur SM, Potter JD, Sellers TA and Folsom AR: Increased risk of breast cancer with alcohol consumption in postmenopausal women. Am J Epidemiol 136: 1221-1231, 1992.

34. Ginsburg ES, Walsh BW, Shea BF, Gao X, Gleason RE and Barbieri RL: The effects of ethanol on the clearance of estradiol in postmenopausal women. Fertil Steril 63: 1227-1230, 1995.

35. Setiawan VW, Monroe KR, Wilkens LR, Kolonel LN, Pike MC and Henderson BE: Breast cancer risk factors defined by estrogen and progesterone receptor status: the multiethnic cohort study. Am J Epidemiol 169: 1251-1259, 2009.

36. Ginsburg ES, Walsh BW, Gao X, Gleason RE, Feltmate C and Barbieri RL: The effect of acute ethanol ingestion on estrogen levels in postmenopausal women using transdermal estradiol. J Soc Gynecol Investig 2: 26-29, 1995.

37. Roth MJ, Baer DJ, Albert PS, et al: Relationship between serum leptin levels and alcohol consumption in a controlled feeding and alcohol ingestion study. J Natl Cancer Inst 95: 1722-1725, 2003.

38. Maskarinec G, Morimoto Y, Takata Y, Murphy SP and Stanczyk FZ: Alcohol and dietary fibre intakes affect circulating sex hormones among premenopausal women. Public Health Nutr 9: 875-881, 2006.

39. Lewis-Wambi JS and Jordan VC: Estrogen regulation of apoptosis: how can one hormone stimulate and inhibit? Breast Cancer Res 11: 206, 2009.

40. Hong J, Holcomb VB, Dang F, Porampornpilas K and Nunez NP: Alcohol consumption, obesity, estrogen treatment and breast cancer. Anticancer Res 30: 1-8, 2010.

41. Hong J, Smith RR, Harvey AE and Nunez NP: Alcohol consumption promotes insulin sensitivity without affecting body fat levels. Int J Obes (Lond) 33: 197-203, 2009.

42. Boffetta P, Hashibe M, La Vecchia C, Zatonski W and Rehm J: The burden of cancer attributable to alcohol drinking. Int $\mathrm{J}$ Cancer 119: 884-887, 2006.

43. Chemical Test Section, Wisconsin Department of Transportation, Division of State Patrol. http://www.dot.wisconsin.gov/safety/ docs/08law.pdf.

44. Zhao JJ and Roberts TM: PI3 kinases in cancer: from oncogene artifact to leading cancer target. Sci STKE 2006: pe52, 2006.

45. Hu KQ, Kyulo NL, Esrailian E, et al: Overweight and obesity, hepatic steatosis, and progression of chronic hepatitis C: a retrospective study on a large cohort of patients in the United States. J Hepatol 40: 147-154, 2004. 
46. Watabiki T, Okii Y, Tokiyasu T, et al: Long-term ethanol consumption in ICR mice causes mammary tumor in females and liver fibrosis in males. Alcohol Clin Exp Res 24: S117-S122, 2000.

47. Meng Q, Gao B, Goldberg ID, Rosen EM and Fan S: Stimulation of cell invasion and migration by alcohol in breast cancer cells. Biochem Biophys Res Commun 273: 448-453, 2000.

48. Huang Z and Sjoholm A: Ethanol acutely stimulates islet blood flow, amplifies insulin secretion, and induces hypoglycemia via nitric oxide and vagally mediated mechanisms. Endocrinology 149: 232-236, 2008

49. Haslam SZ, Osuch JR, Raafat AM and Hofseth LJ: Postmenopausal hormone replacement therapy: effects on normal mammary gland in humans and in a mouse postmenopausal model. J Mammary Gland Biol Neoplasia 7: 93-105, 2002.

50. Nkhata KJ, Ray A, Dogan S, Grande JP and Cleary MP: Mammary tumor development from T47-D human breast cancer cells in obese ovariectomized mice with and without estradiol supplements. Breast Cancer Res Treat 114: 71-83, 2009.

51. Ravdin PM, Cronin KA, Howlader N, et al: The decrease in breast-cancer incidence in 2003 in the United States. N Engl J Med 356: 1670-1674, 2007.

52. Pike MC, Krailo MD, Henderson BE, Casagrande JT and Hoel DG: Hormonal risk factors, breast tissue age and the ageincidence of breast cancer. Nature 303: 767-770, 1983.

53. Chen WY: Exogenous and endogenous hormones and breast cancer. Best Pract Res Clin Endocrinol Metab 22: 573-585, 2008.

54. Rossouw JE, Anderson GL, Prentice RL, et al: Risks and benefits of estrogen plus progestin in healthy postmenopausal women: principal results From the Women's Health Initiative randomized controlled trial. JAMA 288: 321-333, 2002.

55. Beral V: Breast cancer and hormone-replacement therapy in the Million Women Study. Lancet 362: 419-427, 2003

56. Prentice RL, Chlebowski RT, Stefanick ML, et al: Conjugated equine estrogens and breast cancer risk in the Women's Health Initiative clinical trial and observational study. Am J Epidemiol 167: 1407-1415, 2008

57. Hu X, Juneja SC, Maihle NJ and Cleary MP: Leptin-a growth factor in normal and malignant breast cells and for normal mammary gland development. J Natl Cancer Inst 94: 1704-1711, 2002.

58. Vona-Davis L and Rose DP: Angiogenesis, adipokines and breast cancer. Cytokine Growth Factor Rev 20: 193-201, 2009.

59. Sulkowska M, Golaszewska J, Wincewicz A, Koda M, Baltaziak M and Sulkowski S: Leptin-from regulation of fat metabolism to stimulation of breast cancer growth. Pathol Oncol Res 12: 69-72, 2006.
60. Caldefie-Chezet F, Damez M, de Latour M, et al: Leptin: a proliferative factor for breast cancer? Study on human ductal carcinoma. Biochem Biophys Res Commun 334: 737-741, 2005.

61. Neufeld G, Cohen T, Gengrinovitch S and Poltorak Z: Vascular endothelial growth factor (VEGF) and its receptors. FASEB J 13: 9-22, 1999.

62. Folkman J: Angiogenesis in cancer, vascular, rheumatoid and other disease. Nat Med 1: 27-31, 1995.

63. Dabrosin C, Margetts PJ and Gauldie J: Estradiol increases extracellular levels of vascular endothelial growth factor in vivo in murine mammary cancer. Int J Cancer 107: 535-540, 2003.

64. Shimizu H, Shimomura Y, Nakanishi Y, et al: Estrogen increases in vivo leptin production in rats and human subjects. J Endocrinol 154: 285-292, 1997.

65. Bachman KE, Argani P, Samuels Y, et al: The PIK3CA gene is mutated with high frequency in human breast cancers. Cancer Biol Ther 3: 772-775, 2004.

66. Campbell IG, Russell SE, Choong DY, et al: Mutation of the PIK3CA gene in ovarian and breast cancer. Cancer Res 64: 7678-7681, 2004

67. Levine DA, Bogomolniy F, Yee CJ, et al: Frequent mutation of the PIK3CA gene in ovarian and breast cancers. Clin Cancer Res 11: 2875-2878, 2005 .

68. Zhang Y, Zhao H, Asztalos S, Chisamore M, Sitabkhan Y and Tonetti DA: Estradiol-induced regression in T47D:A18/ PKCalpha tumors requires the estrogen receptor and interaction with the extracellular matrix. Mol Cancer Res 7: 498-510, 2009.

69. John S, Nayvelt I, Hsu HC et al: Regulation of estrogenic effects by beclin 1 in breast cancer cells. Cancer Res 68: 7855-7863, 2008.

70. Lewis JS, Meeke K, Osipo C, et al: Intrinsic mechanism of estradiol-induced apoptosis in breast cancer cells resistant to estrogen deprivation. J Natl Cancer Inst 97: 1746-1759, 2005.

71. Osipo C, Gajdos C, Liu H, Chen B and Jordan VC: Paradoxical action of fulvestrant in estradiol-induced regression of tamoxifen-stimulated breast cancer. J Natl Cancer Inst 95: 1597-1608, 2003.

72. Song RX, Mor G, Naftolin F, et al: Effect of long-term estrogen deprivation on apoptotic responses of breast cancer cells to 17beta-estradiol. J Natl Cancer Inst 93: 1714-1723, 2001.

73. Swaby RF and Jordan VC: Low-dose estrogen therapy to reverse acquired antihormonal resistance in the treatment of breast cancer. Clin Breast Cancer 8: 124-133, 2008.

74. Huang XF and Chen JZ: Obesity, the PI3K/Akt signal pathway and colon cancer. Obes Rev 10: 610-616, 2009. 